\title{
Reading Texts in Translation Classes: Discourse Analysis Perspectives
}

\author{
Abdulmuhsen Ayedh Alqahtani \\ Kuwait University, Kuwait \\ Email: abdulmuhsen.alqahtani@ku.edu.kw \\ Ahmad Bashar Aljidy \\ Hail University, Saudi Arabia \\ Email: bouzag@yahoo.com
}

\begin{abstract}
This paper aims at finding out what opportunities discourse analysis can offer in teaching translation. Specifically, it attempts to determine what areas of discourse analysis are relevant to teaching Arabic-English translation at college level as well as to identify what translation instructors and students can borrow from other related disciplines and make use of them in the classroom. A critical review of published theories and models was done to examine the main concepts in this regards. The paper concludes with emphasizing the role of discourse analysis in the shift from target text being purely equivalency-oriented text to a dynamic-oriented text.
\end{abstract}

Index Terms—discourse analysis, discourse, reading

The course syllabus for most translation course worldwide stipulates that the overall aim of the translation course is to enhance students' cultural awareness, and language and competencies. Among the specific goals, reading source and target texts is regarded as one of the priorities in teaching translation as learners are supposed to be critical readers who are able to decode and code texts in order to minimize what is called 'lost in translation.' This characteristic can help them view a given text from different perspectives.

Mastering critical reading abilities require efforts from both translation instructors and students. At this end, discourse analysis is regarded as an approach to do this. Although the theoretical bases of discourse analysis have been available since the 1950s, its use in teaching processes was brought up in the 1980s. Since Cook's Discourse (1989), discourse analysis has become an increasingly popular topic in language teaching research (McCarthy, 1991; McCarthy \& Ronald, 1994; Celce-Murcia \& Olshtain, 2000; Wallace, 2003 et al.).

Although the field of discourse analysis is broad, it is categorized into five major areas in teaching contexts: cohesion, coherence, information structure, turn taking and critical discourse analysis (Celce-Murcia \& Olshtain, 2000). Furthermore, Fairclough (2003) believed that 'textually oriented discourse analysis' is as similar as the term 'discourse analysis,' where the latter is not concerned with the linguistic features of the text.

\section{PURPOSE}

The purpose of this paper is twofold: (a) to examine closely the theoretical evolution of discourse analysis in relation to teaching reading; and (b) to search what opportunities discourse analysis offers in reading texts in translation courses.

\section{DEFINITION}

\section{A. Discourse Analysis}

Discourse analysis is the study of the relationship between language and its intertextual, social and intercultural contexts in which it is used; i.e., it is the linguistic study of the interaction between text and discourse (Cook, 1989; Fairclough, 2003; McCarthy, 1991).

\section{B. Discourse}

Reviewing different schools of thought, Bloor and Bloor (2007) distinguished a number of uses of the term 'discourse' ranging from the understanding of discourse as all symbolic interaction and communication, written or spoken, between people to treating discourse as a particular text (for elaboration see, e.g., Bourdieu, 1997; Brown \& Yule, 1983; Harris, 1952; ). Cook's (1992) definition of discourse is still considered, however, as the definition encompassing the overall elements of its; it is "text and context together, interacting in a way which is perceived as meaningful and unified by the participants" (Cook, 1992, p. 2). The context here is used in the broadest sense, including sender and receiver, the situation, the function, the multimodality, and background knowledge. Blommaert (2005) added to connotation of context what he calls 'forgotten contexts.' These forgotten contexts include resources which 
individuals cannot control, text trajectories (i.e. awareness that every instance of production, reproduction, circulation and consumption of a text involves shifts in contexts) and context data histories.

\section{Reading}

Anderson (2000) pointed out that in reading research, a distinction should be made between the process of reading and the product of reading. In respect to the current study, the process of reading makes up the primary focus. In order to put the text into the context, Lundahl (1998) defined the process of reading as "an active process that involves giving or constructing meaning provided that the text seems meaningful and we can relate the content to our previous experience and knowledge" (p. 9). According to this definition, it is argued that reading is embodied some kind of social nature which makes the process of reading not an individual activity, but also an activity reflecting the members of discourse communities (Wallace, 2003). Thus, the interpretation resulting from the process of reading done in a target discourse community can obviously detach the meanings intended within the original discourse community. Thus, the process of reading in the current study can be defined as a process of receiving and interpreting information encoded in the source discourse community language to be decoded within the context of the target discourse community language.

\section{METHOD}

The current study is based upon the synthesis of the ideas from a wide range of disciplines often studied historically. This approach is classified as a secondary research approach to fulfill the aims of a given study (Brown, 1988; Dörnyei, 2007). According to Tashakkori and Teddlie (1998), the "best method is the one that answers the research question(s) most efficiently" (p. 167); this is the rationale behind choosing this secondary approach.

Materials and Procedures:

Due to the fact that the term 'discourse analysis' is used in a range of disciplines, it is imperative to limit the scope of the research. Such a measurement constituted the first step in the procedures. Disciplines included in the research were applied linguistics, language teaching, and social sciences. The second step was to search for relevant research literature, using keywords such as 'discourse analysis.' The third step was to critically, diachronically study the relevant concepts.

\section{REVIEW OF THE LITERATURE}

\section{A. Discourse Analysis}

The concept of 'discourse analysis' dates back to the beginning if [of the]1950s when Zellig Harris (1952a) introduced it to the scientific community. Thus, he was the first to define discourse analysis as a method for the analysis of connected speech (or writing) that goes beyond the limits of a single sentence and correlates culture and language. Since Harris was primarily interested in so called 'equivalence classes,' however, discourse analysis, he argued, belongs to formal linguistics and does not take into account the semantics of the elements under analysis. The result of such discourse analysis is presented in the form of a double array, or succession of intervals, containing certain equivalence classes.

Although Harris did not intend to address teaching contexts, his suggestions provided [a] number of perspectives in the language teaching contexts. First, it alerts researchers to the link between language and culture, and that teaching language topics cannot be done only within linguistics proper. Regrettably, he did not propose guidelines on employing discourse analysis for that very purpose. For example, the only phrase he illustrated with was 'how are you?' and commented that this is obviously used for social function rather than a question about well-being. Second, Harris (1952a) suggested that a text is composed of a number of sentences that are connected with what he called 'equivalence classes.' To a large extent, this phenomenon is similar to the notion of cohesive devices discussed by Halliday and Hassan (1976). However, Harris did not provide tangible illustrations of how to employ discourse analysis in this regard. Third, Harris paid attention to the fact that each text is characterized by some kind of patterns which goes beyond mere grammar; these patterns constitute what he called the 'dialect' of a given sort of texts.

Harris (1952a) suggested that a discourse analysis should go beyond the boundaries of the sentence level; i.e., reading the whole discourse. In reading texts, to know the dialect in which the text is encoded helps readers to comprehend fast and deeply. This situation goes in line with what Swales (1990) labeled the 'discourse community,' the community that holds particular expectations about how and what to communicate. The most important impact of Harris' germ article is that reading is seen as a process stretching the boundaries of text implications.

What Harris (1952a) did has influenced trends in teaching reading and reading research within the next three decades. Lezberg and Hilferty (1978) pointed out that discourse analysis could have two applications in the reading class: pedagogical and class content. Unlike Harris, they attempted to move discourse analysis from theory to practice, albeit the validity of their case study they reported is questionable in terms of the situational context. They viewed discourse analysis as including learners in introducing, finishing-off, unfolding the topic where the readers can reach "the inner state of the speaker" (Lezberg \& Hilferty, 1978, p. 50). The valuable recommendation they came up with to teachers on how to carry out practical work with reading as discourse in the class were skimming (looking for key words and main ideas) and scanning tasks (looking for details regarding the writing style, cohesive aids, specific information), beforereading activities (such as brainstorming, generating questions about the text, word association activities, discussing and 
defining vocabulary, anticipation activities), after-reading activities (distinguishing between statements and opinions, paraphrasing, noticing language features and forms, matching, arguing discussions for possible bias and propaganda), and reading skill builders (practicing phrase reading and doing timed reading exercises).

Most of those recommendations are implemented in the reading tasks in contemporary language course books so as to be an action plan (McCarthy, 1991). However, it is a must to realize that Lezberg and Hilferty's (1978) ambition is to make learners adopt specific strategies while reading a text that in their understanding constitute discourse analysis rather than developing reading skills (i.e., reading skill builder). While a strategy is an action selected deliberately to achieve particular goals, a skill is a technique applied unconsciously (Hudson, 2007).

Since Brown and Yule's (1983) Discourse Analysis has appeared as the most cited work in the field of discourse analysis, the analysis of language in use has received attention by researchers (for more discussion, see, Blommaert, 2005; McCarthy, 1991). Although they admitted that the concept 'language in use' referring to discourse analysis is crucial in language teaching and provides a solid ground for teaching contexts, they did not provide plausible treatment of the possible application of discourse analysis. Cook' Discourse (1989) elaborated on the issue and outlined some significant trends, although he did not explicitly treat applying discourse analysis. Having defined discourse analysis is as examination of "how stretches of language, considered in their full textual, social, and psychological context, become meaningful and unified for their users" (1989, p. ix), Cook set up a new paradigm in discourse analysis in language teaching. In this regard, Cook's is characterized by three significant themes.

First, Cook (1989) developed Harris's idea of the 'dialect' and pointed out that foreign language learners are 'social outsiders' because they lack the social knowledge that is essential to making text into discourse. Thus, he emphasized that the formal approach to language topics alone (i.e. dealing with facts inside the language system) is not enough for learners to be acquainted with a discourse community. By the same token, understanding lexis and processing grammar do not necessarily provide an adequate comprehension of the text. Second, since he considered foreign readers as social outsiders who lack the experience of typical discourses of source text community, he included knowledge schemata, mental representations of typical situations, in the context to predict the contents of the particular situation (cf. Carrell \& Eisterhold' schematheoretic, 1983; Wallace's taken-forgrantedness, 2003). Third, Cook argued that discourse analysis could help learners adopt top-down approach in reading, where they can set a discourse in its textual and social context. As stated earlier, Cook and others' works on discourse analysis paved the way to teaching-oriented researchers to consider and include it in their works.

\section{B. Language and Metacognitive Awareness}

McCarthy (1991), and McCarthy and Carter (1994) were the first to examine discourse analysis in educational contexts. In contrast to researchers prior to them, especially Guy Cook (1989), McCarthy and Carter (1991) adopted an interactive approach in language teaching where of higher-order operations of language (i.e. cultural and ideological meanings) and lower-order forms of language that both contribute interdependently to patterning the meaning. That is, the readers should be interested not only in the macro-level of a discourse but in the micro-level as well in comprehending a text. The concept of intertextuality is included in analyzing discourse where both language teachers and learners are urged to pay attention to what other immediate texts (i.e., contexts) refers to in order to better understand the text. Following a schema-theoretic approach, McCarthy divided a text into content schemata (i.e., background knowledge), formal schemata (i.e., structures). However, McCarthy and Carter substituted content schemata by cultural frames which became then a parameter of language awareness, namely socio-cultural meaning. Formal schemata were also transformed into two other parameters of language awareness: form and function.

To increase language awareness within the parameters of form and function, learners are encouraged to look at language as a system and to examine what language does in the given context. The rationale behind this trend of research was due to the fact that a text does not exist in a vacuum but naturally refers to other texts that are essential for its understanding. The shift from a schemata-view to a language-awareness-view was an apt one in terms of pedagogy. Thus, language awareness, being defined as "the development in learners of an enhanced consciousness of and sensitivity to the forms and functions of language" (Carter, 2003, p.64) was seen as an ability, while schemata, described as "the previously acquired knowledge structures" (Carrell and Eisterhold, 1983, p. 556), were seen as factual information. Of course, they by no means meant to devaluate the schemata theory in language learning and teaching, but rather they emphasized the potentiality of incorporating it in language education.

Based on what has been said so far, Celce-Murcia and Olshtain (2000) believed that discourse analysis is an umbrella term for all studies that concern text and discourse. Therefore, Celce-Murcia and Olshtain suggested that [that] discourse analysis studies have led to a transition from a grammar-oriented approach of language teaching to a discourse-oriented one, and, consequently to the goal of teaching language for communication. One feature that CelceMurcia and Olshtain added to discourse-oriented approach of language education was, however, a metacognitive awareness where they refined the interpretation process. Metacognitive awareness is meant to connect top-down and bottom-up processing and, can, thus, be seen as an essential part of the interactive nature of language education, reading in particular.

\section{Critical Reading}


In all language education aspects, the most consistent application of discourse analysis is in done when reading materials. Wallace $(1992,2003)$ argued for critical reading that is based on critical discourse analysis, a study of how language and power are related (Fairclough, 1989), critical language awareness, an awareness of the ideological role of language (Wallace, 1992). Moreover, Wallace introduced metacritical awareness to indicate the challenge of separating oneself from one's interpretations.

Reading foreign texts is more sensitive to taken-for-granted knowledge; that is, foreign readers activate schemata that tend to reinforce taken-for-grantedness (Wallace, 2003). According to Wallace (1992; 2003), this phenomenon gives legitimacy to practice discourse analysis, including critical reading, in foreign language contexts where three goals can be achieved:

- reflecting upon the language choice;

- developing argumentative capabilities; and

- promoting cross-cultural awareness.

These three goals can be approached in theoretical and practical ways (Wallace, 2003). From a theoretical perspective, not only do all texts reflect certain ideology, but they are interpreted from another ideological standpoint. In another words, reading a text is a social process where its meanings are negotiated within discourse communities. On the practical level, however, as the meanings embodied in a text are negotiated, there is a balance of power distribution among all those who are concerned in the reading process.

Combining the theoretical and practical approaches to reading, readers, either language instructors or learners, who read a text, can divide the reading process into three stages (Wallace, 1992; 2003):

1. pre-reading: the topic of the text, the choice of the topic, the way the topic was written, alternative ways to cover the topic, and the relationship between write and reader;

2. while-reading: deciphering the implications of the text and negotiate them with other members of the discourse community; and

3. post-reading: what happened after reading the text; is there any change in attitudes or improvement of knowledge, for example?

These three stages can be used in parallel with the Hallidayan grammar. That is, readers can focus on the field of the text (i.e., what is going on), the tenor (i.e., interpersonal relations), and the mode (i.e., text organization); these three Hallidayan elements can and do help readers to focus on the effect of the writer's choice. The whole framework for textual analysis in critical reading is presented in figure 1 (see, Wallace, 2003, p. 39). 


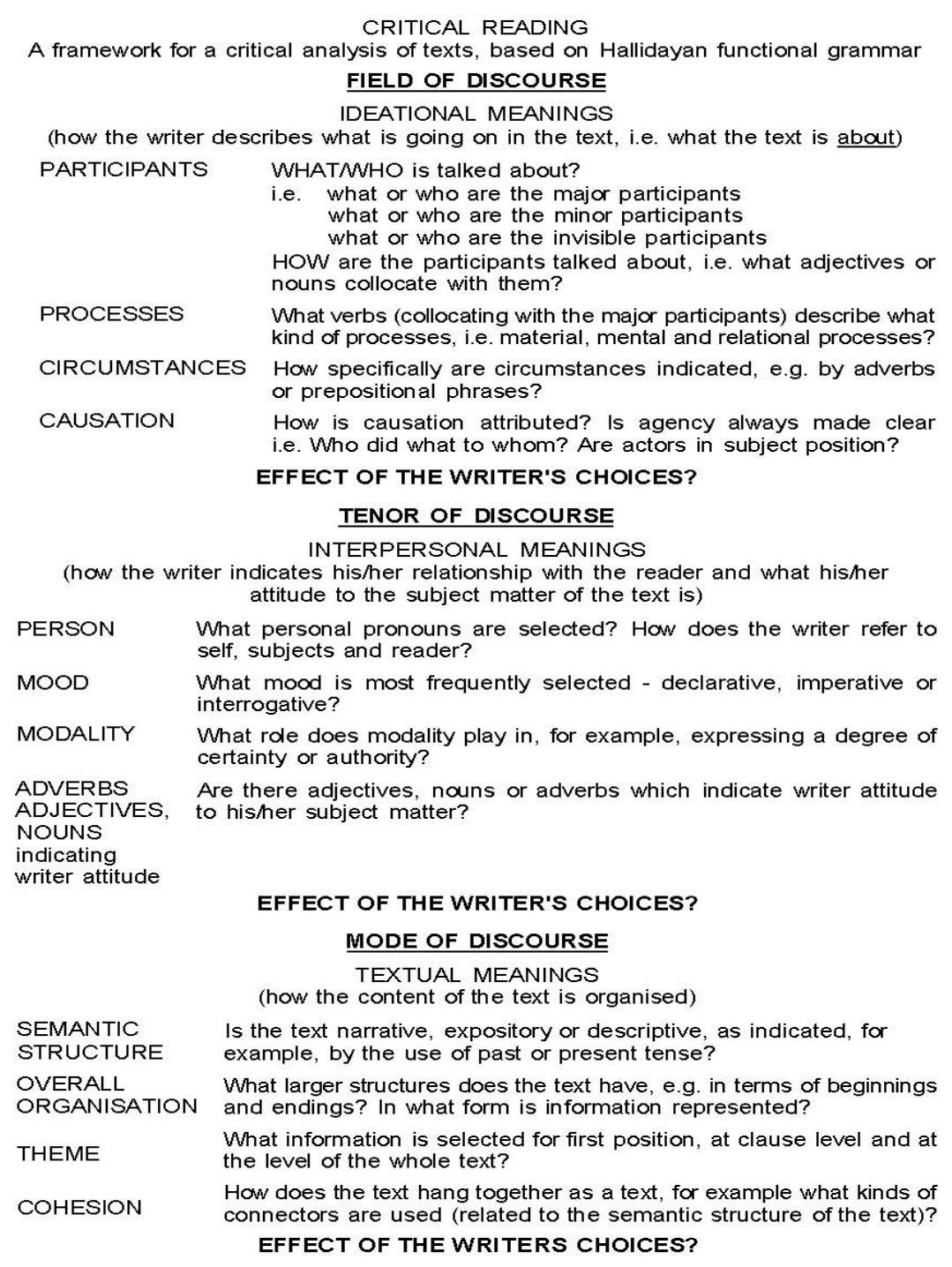

Figure 1. The framework for textual analysis in critical reading (Wallace, 2003, p. 39)

As shown in figure 1, Wallace (2003) proposed a practical application of discourse analysis in reading contexts, acknowledging the importance of language and metacognitive awareness. Although she tended to diminish the role of the author's communicative intent and is primarily concerned with the effect it causes, based on her belief that reading is a social process of negotiating the meaning in the discourse community, she still stressed the significance of metacritical awareness and critical language awareness in critical reading.

On the same line of argumentation, Cots (2006) believed that, in addition to using the conventional way in reading, he emphasized the use of critical discourse analysis at three levels: social practice, discursive practice, and textual practice. At the social level, the representation of the world is examined in the light of the influence of the writer's ideology on the text, and the effect of the text on the target readers (cf. the content schemata or taken-for-granted knowledge). At the level of discursive practice, the communicative situation of the text is studied: its genre, textual links, the structure of propositions and coherence (cf. formal schemata), all are in the light of readers' experience. Finally, at the textual practice level, the focus is on the formal and semantic features: connectors, modality, and vocabulary. This third level reflects how readers create the representation of the world while reading. In short, Cots proposed that discourse analysis helps deal with discovering and understanding the text by using sharp observational skills for informed choices and interpretation.

\section{CONCLUSION AND RECOMMENDATIONS}

The current paper attempted to explore, in general, the contribution of discourse analysis to the paradigm shift in reading. To accomplish this purpose, the models of discourse analysis proposed by Wallace $(1992,2003)$ and Cots (2006) were adopted to demonstrate how to place texts in their social, cultural and intertextual contexts in order to 
become a more effective reader. At this point, it is possible to conclude with some discourse-oriented pedagogical implications for translation classes (McCarthy, Matthiessen \& Slade, 2002).

When teaching translation is as a set of choices, reading texts are also seen as structures in different contexts of use. Thus, it enables language instructors and material designers to delineate genres that are essential and relevant to particular learners' needs and to include them in class content and textbooks. A discourse-oriented approach can encourage as well learners to develop language awareness, exploring relationships between form, meaning and use. From a cognitive perspective, Grabe (2009) argues for building awareness of discourse through several techniques, mainly through highlighting key words that signal text structure, identifying a paragraph's function, and finding patterns of discourse organization in a text. Finally, a discourse-oriented approach can allow instructors to evaluate interactions within the classroom (McCarthy, Matthiessen \& Slade, 2002) in order to enhance understanding.

Although Harris (1952a; 1952b) did not provide clear guidelines on how to manage discourse analysis, he initiated the discussion about the correlation between stretches of language longer than a sentence and culture with the aid of cohesive tools in the text and the dialect in which the text is written (cf. genre). As a result cohesive aids and genres became a core component in teaching reading, focusing on longer language segments, which later made the top-down approach to reading possible.

\section{REFERENCES}

[1] Alderson, C. (2000). Assessing reading. Cambridge: Cambridge University Press.

[2] Blommaert, J. (2005). Discourse: A critical introduction. Cambridge: Cambridge University Press.

[3] Bloor, M., \& Bloor, T. (2007). The practice of critical discourse analysis: An introduction. London: Hodder Arnold.

[4] Bourdieu, P. (1997). Language and symbolic power. Cambridge: Polity in association with Basil Blackwell.

[5] Brown, Gillian \& Yule, George. (1983). Discourse analysis. Cambridge: Cambridge University Press.

[6] Brown, J. (1988). Understanding research in second language learning: A teacher's guide to statistics and research design. Cambridge: Cambridge University Press.

[7] Carrell, P., \& Eisterhold, J. (1983). Schema theory and ESL reading pedagogy. TESOL Quarterly, vol. 17: 4, pp. $553-573$.

[8] Carter, R. (2003). Language awareness. ELT Journal, 57, 64-65.

[9] Celce-Murcia, M., \& Olshtain, E. (2000). Discourse and context in language teaching: A guide for language teachers. Cambridge: Cambridge University Press.

[10] Cook, G. (1989). Discourse. Oxford: Oxford University Press.

[11] Cook, G. (1992). The discourse of advertising. London and New York: Routledge.

[12] Cots, J. (2006). Teaching 'with an attitude': Critical discourse analysis in EFL teaching. ELT Journal, 60, 336-345.

[13] Dörnyei, Z. (2007). Research methods in applied linguistics. Oxford, New York: Oxford University Press.

[14] Fairclough, N. (2003). Analysing discourse: Textual analysis for social research. London: Routledge.

[15] Grabe, W. (2009). Reading in a second language: Moving from theory to practice. Cambridge: Cambridge University Press.

[16] Fairclough, N. (1989). Language and power. London: Longman.

[17] Halliday, M., \& Hasan, R. (1976). Cohesion in English. London: Longman.

[18] Harris, Z. (1952a). Discourse analysis. Language, 28, 1-30.

[19] Harris, Z. (1952b). Discourse analysis: A sample text. Language, 28, 474-494.

[20] Hatt, F. (1976). The reading process: A framework for analysis and description. London: Clive Bingley.

[21] Hudson, T. (2007). Teaching second language reading. Oxford, New York: Oxford University Press.

[22] Lezberg, A., \& Hilferty, A. (1978). Discourse analysis in the reading class. TESOL Quarterly, 12, 47-55.

[23] McCarthy, M. (1991). Discourse analysis for language teachers. Cambridge: Cambridge University Press.

[24] McCarthy, M., Matthiessen, C., \& Slade, D. (2002). Discourse analysis. In Schmitt, N. (Ed.), An introduction to applied linguistics (pp. 55-73). London: Arnold.

[25] McCarthy, Michael \& Carter, Ronald. (1994). Language as discourse: Perspectives for language teaching. London: Longman.

[26] Nunan, D. (1999). Second language teaching \& learning. Boston, Massachusetts: Heinle \& Heinle.

[27] Östman, J., \& Virtanen, T. (1995). Discourse analysis. In Verschueren, J., Östman, J., \& Blommaert, J. (Eds.), Handbook of pragmatics (pp. 239-253). Amsterdam: John Benjamins.

[28] Swales, J. (1990). Genre analysis: English in academic and research settings. Cambridge: Cambridge University Press.

[29] Tashakkori, A., \& Teddlie, C. (1998). Mixed methodology: Combining qualitative and quantitative approaches. Thousand Oaks, California: Sage.

[30] Urquhart, A., \& Weir, C. (1998). Reading in a second language: Process, product, and practice. London and New York: Longman.

[31] Wallace, Catherine. (1992). Critical literacy awareness in the EFL classroom. In Fairclough, N. (Ed.), Critical language awareness (pp. 59-93). London and New York: Longman.

[32] Wallace, C. (2003). Critical reading in language education. New York: Palgrave Macmillan.

Abdulmuhsen Ayedh Alqahtani (Kuwait, 1970). BA in ELT (Kuwait University, Kuwait, 1994); MA in Computational Linguistics (University of Essex, UK, 1998); PhD. in Educational Leadership \& Policy Studies (Virginia Tech., USA, 2007); PhD. in Applied Linguistics (University of London, UK, 2007)

He worked as a high school ELT teacher, Kuwait, then worked as a faculty of ELT and ESP in the College of Basic Education, Kuwait, and currently as a faculty of educational management and planning, Kuwait University, Kuwait. Research interests include 
broad areas of applied linguistics and translation studies, and educational leadership \& policy studies. He has various journal and conference publications in the areas of his interests.

Dr. Abdulmuhsen Ayedh Alqahtani is a member of some national and international professional societies related to his areas of interests. He is a member as in several academic and professional committees.

Ahmad Bashar Aljidy is an academic staff member at Hail University, Kingdom of Saudi Arabia. Currently he is teaching English language course in the preparation year. His research interests include language teaching and learning, and sociolinguistics. 